\title{
Performance of the pigeon on the ambiguous-cue problem*
}

\author{
RALPH W. RICHARDS \\ Colorado State University, Fort Collins, Colo. 80521
}

Three pigeons were trained on the two-choice ambiguous-cue problem which involves three stimuli: a positive stimulus, to which responding is always reinforced, a negative stimulus, to which responding is never reinforced, and an ambiguous stimulus, to which responding is sometimes reinforced and sometimes not reinforced, depending on which of the other stimuli is simultaneously presented. Using distinctively colored stimuli, all Ss quickly learned to choose the ambiguous stimulus when it was paired with the negative stimulus. Ss also learned, although more slowly, to choose the positive stimulus when it was paired with the ambiguous stimulus.

One of the most interesting of the complex discrimination problems is the ambiguous-cue problem. This two-choice problem involves three stimuli: a positive stimulus $(\mathrm{P})$, to which responding is always reinforced, a negative stimulus $(N)$, to which responding is never reinforced, and an ambiguous stimulus (A), to which responding is sometimes reinforced and sometimes not reinforced, depending on which of the other stimuli is simultaneously presented. Specifically, each $S$ is presented with two types of trials, PA trials, and NA trials, in some mixed order. On PA trials, the S must choose between the positive and ambiguous stimuli; on NA trials, the S must choose between the negative and ambiguous stimuli. Choice of the ambiguous stimulus is reinforced on NA trials, but is not reinforced on PA trials. When each of the stimuli possesses distinctive properties, the consistent finding (Leary, 1958; Zeaman \& House, 1962; Boyer, Polidora, Fletcher, \& Woodruff, 1966; Fletcher, Grogg, \& Garske, 1968; Fletcher \& Garske, 1972; Boyer \& Polidora, 1972) has been that the NA trials are learned faster and are learned to a higher terminal level than the PA trials.

The Ss in the above studies were either human or nonhuman primates. The purpose of the present experiment was to determine if the more economical and more readily available pigeon could learn the ambiguous-cue problem and, if so, to compare its performance with that of primates.

\section{METHOD \\ Subjects}

Three adult female White Carneaux pigoens, obtained from the Palmetto Pigeon Plant, were maintained at approximately $70 \%$ of their free-feeding weights. Several weeks prior to the present experiment, the keypecking of these Ss was partially shaped to a white key.

* This research was supported by BSSG Grant 5 S05 RR07127-03. Reprints may be obtained from the author, Department of Psychology, Colorado State University, Fort Collins, Colorado 80521. William N. Boyer sponsors this paper and takes full editorial responsibility for it.

\section{Apparatus}

The side keys of a standard three-key operant conditioning chamber could be illuminated by a very pale yellow-orange, an orange, red, or green light from a Lehigh Valley Electronics lamp (Model 11-05); the center key was covered with masking tape. During presentation of the reinforcer, $2.5 \mathrm{sec}$ access to mixed grain, the key lights were extinguished. The standard houselight (CM1820) was illuminated throughout each session, which began and ended in complete darkness. The chamber's ventilation fan provided the only masking of sounds produced by the standard programming and recording equipment which was located in the same room as the chamber.

\section{Preliminary Training}

After the keypeck response was shaped to the right key, Ss received three additional sessions of continuous reinforcement; the left key remained dark and nonfunctional during these sessions. Ss then received three sessions of continuous reinforcement for responding to the left key, with the right key remaining dark and nonfunctional. The operative key was illuminated by the very pale yellow-orange light during these sessions which terminated after 60 reinforced responses.

\section{Discrimination Training}

During the discrimination training sessions, both keys were illuminated at the beginning of a trial so as to present one of the following problems: (a) PA, with the positive stimulus on the right key, (b) PA, with the positive stimulus on the left key, (c) NA, with negative stimulus on the right key, or (d) NA, with negative stimulus on the left key. The order of the problems was random within each session with three restrictions. First, each problem was presented five times in each of the three blocks of 20 trials that constituted a session. (A power failure terminated S-2750's fifth session, and S-7899's twenty-first session after 51 and 34 trials, respectively.) Second, none of the problems could be presented more than three times in succession. Third, on a given session, all birds received the same ordering of problems.

Each trial terminated after one response. A correct response produced the reinforcer which was followed by a 7.5-sec timeout; an incorrect response produced only a 10 -sec timeout. The keys were dark and nonfunctional during the timeout periods. All Ss received 25 sessions of discrimination training with a noncorrection procedure. Since S-7899 failed to learn the PA problem during these sessions, it was given 15 additional sessions of training with a correction procedure. Thus, during these sessions which terminated after the sixtieth reinforced trial, each problem was repeated until the $S$ responded correctly.

In order to make the transition from preliminary training to discrimination training, it was necessary to deliver several free reinforcers to S-2750 during each of the various problems. Between the last day of preliminary training and the first day of discrimination training, S-2333 received 50 discrimination trials which were separated by either a 2.5 -sec presentation of food or a 2.5-sec timeout. These trials will not be mentioned further.

The $\mathbf{P}, \mathbf{N}$, and A stimulus lights were, respectively: green, red, and orange for S-2333, red, orange, and green for S-2750, and orange, green, and red for S-7899.

\section{RESULTS}

Figure 1 presents each S's performance on both the PA and NA trials (indicated by triangles and circles, respectively) over the 25 sessions of discrimination training under the noncorrection procedure. In 


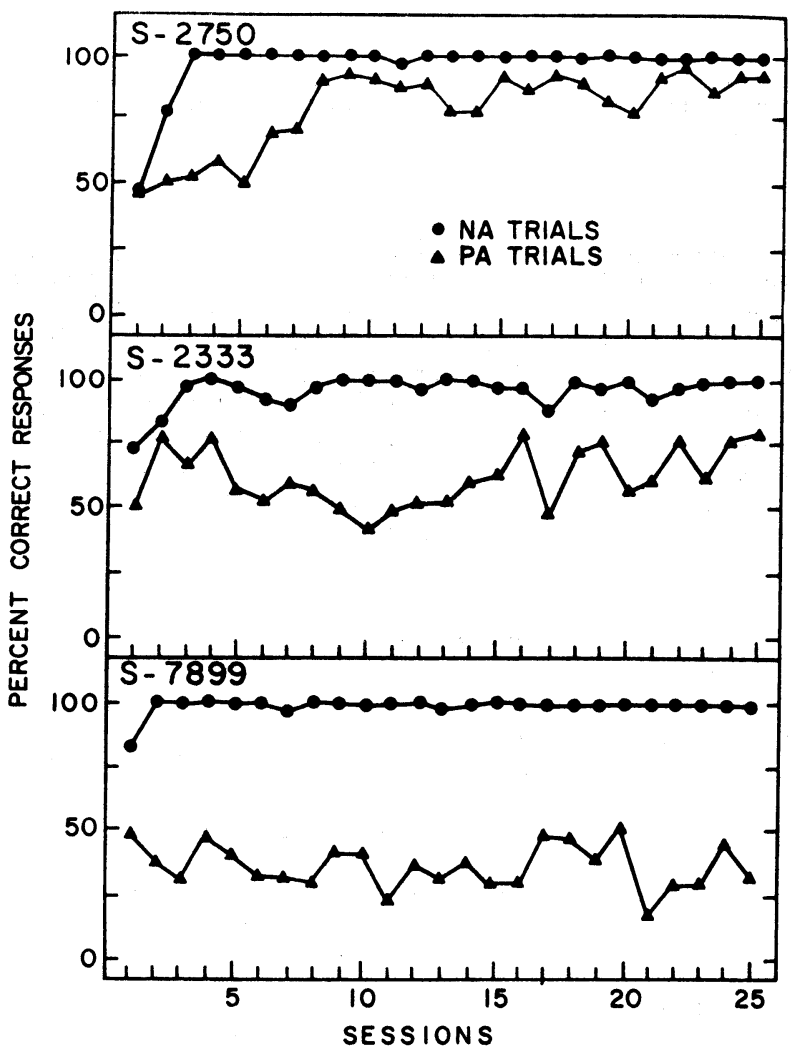

Fig. 1. Performance on PA trials (triangles) and NA trials (circles) over the 25 sessions of discrimination training with the noncorrection procedure. Each session's data are based on PA and NA performance irrespective of the location of the stimuli on the keys.

constructing this figure, the $15 \mathrm{PA}$ trials with the $\mathrm{P}$ stimulus on the right key were combined with the 15 PA trials with the P stimulus on the left key. The NA trials were similarly combined. It is clearly evident that all Ss

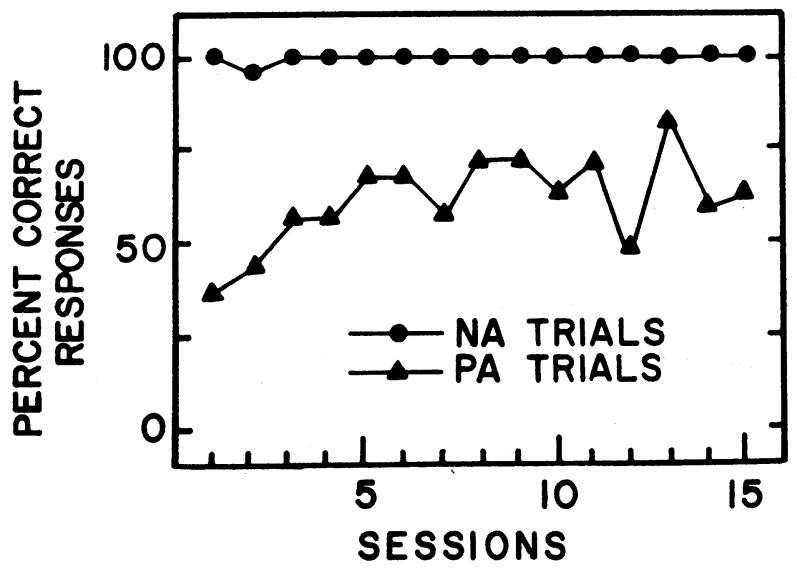

Fig. 2. S-7899's performance on PA trials (triangles) and NA trials (circles) over the 15 sessions with the correction procedure. Each session's data are based on PA and NA performance irrespective of the location of the stimuli on the keys. Performance on the repetitions of a trial due to errors made by the $\mathbf{S}$ were not included in the consturction of this figure. quickly learned to choose A on the NA trials, their performance reaching asymptote within two or three sessions. The asymptote for S-2750 and for S-7899 was at $100 \%$; the asymptote for S-2333 appeared to be between $95 \%-100 \%$. Subject 2750 also learned to choose $\mathrm{P}$ on the PA trials with its performance reaching asymptote after about eight sessions, although there was substantial between-session variability. Subject 2333's PA performance was also clearly above chance (50\%) and also characterized by substantial between-session variability. However, neither S-2750's nor S-2333's PA level of performance reached their NA level of performance. Subject 7899 performed consistently below chance on the PA trials through these 25 sessions under the noncorrection procedure. However, as shown in Fig. 2, the correction procedure was successful in raising S-7899's PA performance above the chance level.

\section{DISCUSSION}

Two of the Ss in the present experiment solved both the PA and the NA trials of the ambiguous-cue problem under a noncorrection procedure. The third $S$, however, required a correction technique to master the PA trials. Consistent with the performance of primates under comparable procedures (Leary, 1958; Zeaman \& House, 1962; Boyer, Polidora, Fletcher, \& Woodruff, 1966; Fletcher, Grogg, \& Garske, 1972; Boyer \& Polidora, 1972), the pigeons learned NA trials faster and to a higher terminal level than PA trials.

In accounting for superior performance on NA trials, Leary proposed a Spencian model that was termed the interfering-cue hypothesis by Zeaman and House. According to this hypothesis, $\mathbf{P}$, because responding to it is always reinforced, acquires approach value, and $\mathrm{N}$, because responding to it is never reinforced, acquires avoidance value. Responding to $A$, however, is sometimes reinforced and sometimes not reinforced. With the additional assumption that the increment in approach value following reinforcement is greater than the increment in avoidance value following nonreinforcement, Leary suggested that $A$ possesses net approach value. Thus, NA performance is superior to PA performance because on PA trials both stimuli possess approach value, and the animal is exposed to an approach-approach conflict. On NA trials, there is no conflict, since $\mathrm{A}$ has approach value and $\mathrm{N}$ has avoidance value. The present results are, of course, compatible with this hypothesis.

Using slightly different procedures, Thompson (1954) and Fletcher \& Bordow (1965), however, reported superior PA performance. In considering these results, which were obtained with two-dimensional plaque stimuli, Medin (1972) suggested that NA trials are learned faster than PA trials, if, and only if, the stimuli are three-dimensional objects. Obviously, the present results, as well as those reported by Boyer \& Polidora (1972) ${ }^{1}$, are incompatible with Medin's suggestion.

Except for the greater number of trials required for mastery, the pigeon's performance on the ambiguous-cue problem was comparable to that reported for primates. The pigeon would, thus, seem an excellent subject for future work on the ambiguous-cue problem.

\section{REFERENCES}

Boyer, W. N., Polidora, V. J., Fletcher, H. J., \& Woodruff, W. Monkey's performance on ambiguous-cue problems. Perceptual \& Motor Skills, 1966, 22, 883-888.

Boyer, W. N., \& Polidora, V. J. An analysis of the solution of PAN ambiguous-cue problems by rhesus monkeys. Learning \& Motivation, 1972, 3, 325-333.

Fletcher, H. J., \& Bordow, A. M. Monkey's solution of an ambiguous-cue problem. Perceptual \& Motor Skills, 1965, 21, 115-119.

Fletcher, H. J., \& Garske, J. P. Response competition in 
monkeys' solution of PAN ambiguous-cue problems. Learning \& Motivation, 1972, 3, 334-340.

Fletcher, H. J., Grogg, T. M., \& Garske, J. P. Ambiguous-cue problem performance of children, retardates, and monkeys. Journal of Comparative \& Physiological Psychology, 1968, 66, 477-482.

Leary, R. W. The learning of ambiguous-cue problems by monkeys. American Journal of Psychology, 1958, 71, 718-724.

Medin, D. L. Role of reinforcement in discrimination learning set in monkeys. Psychological Bulletin, 1972, 77, 305-318.

Thompson, $\mathbf{R}$. Approach versus avoidance in an ambiguous-cue discrimination problem in chimpanzees. Journal of Comparative \& Physiological Psychology, 1954, 47, 133-135.
Zeaman D. \& House, B. J. Approach and avoidance in discrimination learning of retardates. Child Development, 1962, 33, 355-372.

\section{NOTE}

1. Boyer \& Polidora (1972) provide an empirical clarification regarding the apparently contradictory finding of superior performance as reported by Thompson (1954) and by Fletcher \& Bordow (1965).

(Received for publication November 15, 1972.)

\section{A methodological critique of research on "superstitious" behavior}

\author{
HANK DAVIS \\ University of Guelph, Guelph, Ont., Canada \\ JAMES HUBBARD \\ University of Tennessee, Knoxville, Tenn.
}

and

DOUGLAS REBERG

University of Western Ontario, London, Ont., Canada

Much recent research on superstitious behavior involves a procedure in which an instrumental response is pretrained and its rate of occurrence later recorded during a schedule of nonresponse-contingent reinforcement. It is argued that because this procedure fails to take into account the variety of alternative behaviors which might simultaneously be maintained by adventitious reinforcement, the data derived from such research cannot provide best evidence, whether positive or negative, for the general notion of superstitious behavior. The direct observational procedure originally employed by Skinner (1948) is proposed as being necessary for a more sensitive analysis of superstitious behavior.

In 1948, Skinner demonstrated that pigeons given regular deliveries of food emitted stereotyped patterns of behavior prior to each food delivery despite the fact that food was in no way contingent upon these repeated behaviors. This phenomenon, which is now referred to as "superstitious" behavior, is presumed to result from adventitious reinforcement or chance pairings between the "superstitious" operant and food delivery. " For some reason, since the publication of Skinner's 1948 paper, most research on superstition has replaced Skinner's direct observation technique with an analysis of superstition in which the data are obtained by measuring the rate of a single pretrained behavior, such as barpressing or keypecking, during a schedule of response-independent reinforcement (e.g., Neuringer, 1970). This approach is in keeping with the operant experimental tradition of automated data collection and is typified in the statement by Zeiler that the effects of "response independent reinforcement [are] studied more easily if the response is known, rather than if the experimenter must wait for some behavior to emerge through adventitious reinforcement [1968, p. 408].'

It is the purpose of the present paper to argue against the analysis of superstition in terms of the rate of a single behavior, and in favor of the direct observational method originally employed by Skinner (1948). The argument, stated simply, is that during nonresponse-contingent food delivery one cannot be sure which behaviors will be affected by contiguity with food; therefore, to record the occurrence of only one behavior reduces the sensitivity of the analysis and calls the conclusions into question. In making this argument, the conclusions of a particular paper will be the focal point of our criticism, not because the methods 